\title{
Predicting sexual risk behavior in British and European Union university students in the United Kingdom
}

\author{
Rusi Jaspal ${ }^{1}$, Barbara Lopes ${ }^{2}$, Liam Wignall ${ }^{3}$ \& Claire Bloxsom $^{1}$ \\ ${ }^{1}$ Nottingham Trent University, UK; ${ }^{2}$ Universidade de Coimbra, Portugal; ${ }^{3}$ University \\ of Bournemouth, UK
}

\begin{abstract}
Drawing on the Health Adversity Risk Model, this study examines the relationship between mental health and sexual risk behaviors in British and European Union (EU) university students in the United Kingdom. Four hundred and thirty-one undergraduate students completed a cross-sectional survey. Data were analyzed using independent samples t-tests, multiple regression and structural equation modeling. Results showed that female students and British students exhibited higher levels of psychological distress, self-harm and sexual risk behaviors than males and EU students; and that female and EU students were more likely to adopt adaptive coping styles than male and British students, respectively. The structural equation model suggests that the relationship between gender and citizenship and sexual risk-taking is mediated by identity threat, psychological distress, coping styles and self-harm. Adaptive coping styles are not necessarily protective against sexual risk-taking but rather determine the type of sexual risk behavior: re-thinking/planning is associated with volitional risk behaviors and social engagement with non-volitional behaviors. Social and cultural norms may shed light on mental health outcomes and sexual risk-taking in university students.
\end{abstract}

\section{Keywords}

university students, sexual risk, identity threat, psychological distress, self-harm, Health Adversity Risk Model

\section{Corresponding author}

Professor Rusi Jaspal, Department of Psychology, Nottingham Trent University, Nottingham NG1-4FQ, E-mail: rusi.jaspal@,cantab.net

\section{Citing this article}

Jaspal, R. Lopes, B., Wignall, L., \& Bloxsom, C. (2021). Predicting sexual risk behavior in British and European Union university students in the United Kingdom. American Journal of Sexuality Education. https://doi.org/10.1080/15546128.2020.1869129 


\section{Introduction}

University students, and young people in general, are at greater risk of poor sexual health compared to the general population (Chanakira et al., 2014; Public Health England, 2019). There are multiple social and psychological factors that can increase the risk of poor sexual health among students. Yet, there is only limited empirical research into sexual risk-taking behavior in this population (Jaspal, 2020). Drawing on the Health Adversity Risk Model (Jaspal \& Bayley, 2020), this study examines the predictors of sexual risk-taking behaviors in a cross-sectional survey study of British and European Union (EU) ${ }^{1}$ university students in the United Kingdom (UK). In view of the observed peer pressure and difficulties in discussing and negotiating sexual behavior among students (e.g. Chanakira et al., 2015), there is a particular focus on the predictors of volitional and non-volitional sexual behaviors in this population.

\section{Sexual health in young people}

The incidence of sexually transmitted infections (STIs) in people aged 15-24 in the UK is high, and most undergraduate university students are within this age group (Department of Education, 2017). At the end of 2017, 420,000 STI diagnoses were made in England, 144,000 of which (34.2\%) were among those aged 15-24 (Public Health England, 2018). In 2017, 63\% of all cases of chlamydia and 37\% of gonorrhea cases (two of the most common STIs) were among individuals in this age bracket. According to Public Health England (2019), between 2017 and 2018, the incidence of gonorrhea increased by $24 \%$ (from 16,517 to 20,453) and that of syphilis by $11 \%$ (from 950 to 1055). There is evidence that young people, including undergraduate university students, do not regularly engage with sexual health services or screen for STIs (Martin-Smith, Okpo \& Bull, 2018).

\section{Students at British universities}

British universities are diverse in terms of age, gender, and geographical origin. The Department of Education (2017) reported that almost half of all young people now embark upon a university education. In 2017/2018, 139,000 EU citizens were studying at British universities (Hubble \& Bolton, 2019). British universities are a key space in which students socialize, make friends and indeed meet potential sexual partners. In the university context, issues concerning sexual identity development are an important consideration - some students report limited sexual freedom while living with their parents, which may curtail their ability to express their sexual identities (Jaspal, 2020). Conversely, the university experience is often perceived as providing freedom, independence and autonomy. For some, this can involve sexual exploration and, thus, universities are an important context in which to examine the predictors of such behavior.

\section{Sexual risk-taking behavior in students}

In this study, we differentiate between volitional and non-volitional sexual risk behaviors. Volitional sexual risk behaviors are generally pursued with increased

\footnotetext{
1 In the United Kingdom higher education sector, a distinction has long been made between 'Home' (United Kingdom) and European Union (EU) students, even when the United Kingdom was itself a member of the European Union. It is acknowledged that the EU is a broad category. However, the EU students who participated in this particular study came from Poland (40\%), Greece (25\%) and Cyprus $(15 \%)$, all of which are considered culturally and religiously conservative countries with a socially hierarchical/ collectivist cultural orientation (Hofstede, 2008). In this article, the term 'EU students' is used to refer to this subsample of participants.
} 
personal agency (i.e., because one wishes to) and includes vaginal, anal and oral sex without condoms. Conversely, non-volitional behaviors reflect a type of sexual risk-taking that one pursues with limited personal agency (i.e., because one feels coerced or is being paid to do so). French, Tilghman and Malebranche (2015) note the significance of studying non-volitional sexual behaviors in both female and male students, not least because of their association with poor sexual health outcomes (French, Tilghman \& Malebranche, 2015). Non-volitional behaviors represent a particular type of sexual risk-taking that has a clear interpersonal focus in that one is coerced by someone else. However, it is acknowledged that, in some cases, sexual behaviors which we conceptualize as volitional may sometimes involve interpersonal coercion.

Risk factors for poor sexual health are social, environmental and psychological in that both the campus environment and students' social and psychological experiences may, collectively, contribute to risk behaviors (Jaspal, 2020). Many of the key risk factors, such as inaccurate risk appraisal, peer pressure, negative attitudes toward condoms, low psychological wellbeing, and the construal of sexual health in terms of birth control have been discussed elsewhere (e.g. Collado et al., 2016; Gardner \& Steinberg, 2005; Goundry, Finlay \& Llewellyn, 2013; Milhausen et al., 2013).

Self-harm may be an important causal variable in the context of sexual risk-taking. Self-harm has been found to be associated with decreased problem-solving ability in response to psychological adversity, such as adverse early experiences (Slee et al., 2008), which is also associated with sexual risk-taking behaviors in adulthood (Senn \& Carey, 2010). Whether or not self-harm is associated with sexual risk-taking behaviors remains an empirical question. Although female students appear to be at higher risk of self-harm than male students (Gratz, Conrad \& Roemer, 2002), it is unclear whether there are differences between British and EU students. However, in view of the finding that European cultures tend to emphasize commitment to others over self-interest, suggesting a more collectivist cultural orientation (Vignoles, Smith, Becker \& Easterbrook, 2018), it is possible that EU students adopt other more socially oriented coping styles and that they are, thus, at lower risk of self-harm.

\section{Health Adversity Risk Model}

The Health Adversity Risk Model (Jaspal \& Bayley, 2020) provides an integrative, multi-level framework within which the risk of health adversity (e.g. poor sexual health outcomes) can be predicted. The model attempts to articulate the pathways between situational stressors, identity threat, negative affect, coping and health outcomes (see Figure 1). In this study, tenets of the Health Adversity Risk Model are tested to shed light on sexual risk-taking in undergraduate university students.

\section{*Insert Figure 1 here*}

University students appear to face multiple social psychological stressors, which include feeling homesick, academic pressures, and the need to 'fit in' (e.g. Binfet \& Passmore, 2016). These can lead to identity threat, that is, challenge the desirable end-states of identity which people strive to achieve. These 'identity principles' include self-esteem, continuity, distinctiveness and self-efficacy (Breakwell, 1986). The model predicts that identity threat can lead to negative affective states, such as psychological distress. Previous research suggests that the social psychological stressors experienced by male and female students are different and that females may 
be at greater risk of distress (Stallman, 2010). Moreover, it is possible that students from societies which emphasize commitment to others and in which social support is more readily available (Vignoles et al., 2008) will react less adversely to such situational stressors and, thus, experience less identity threat and better psychological wellbeing.

The Health Adversity Risk Model postulates that the threatened individual will react by engaging in coping strategies. Adaptive coping styles generally lead to positive, sustainable outcomes and include inter alia planning and re-thinking, social engagement, and self-change. Maladaptive styles are usually 'quick-fix' strategies that are unsustainable in the long term - they include denial and concealment/ pretense. Some research suggests that male students may feel less able than females to seek social support from others in the face of psychological adversity and, thus, conceal this from others (Morgan, Ness \& Robinson, 2003). Similarly, in view of the more collectivist cultural orientation of some EU countries, students from these societies may favor more socially oriented coping styles.

In the context of sexual health, condomless sex, sex with multiple casual partners, and sex while under the influence of substances can be regarded as maladaptive coping behaviors (Dariotis \& Chen, 2020). Psychological distress may lead to sexual risk behaviors because of decreased motivation to engage in self-care, for instance (Choi, Bowleg \& Neilands, 2011). As sexual health is often construed by students in terms of avoiding unwanted pregnancy, female students may engage in more risk behavior than male students in view of hormonal contraception (Milhausen et al., 2013). However, the relationship between coping styles (both adaptive and maladaptive) and sexual risk behaviors is poorly understood. Re-thinking/planning represents a problem-solving coping style which may lead individuals to take calculated risks (i.e. volitional behaviors). Conversely, social engagement, though a generally adaptive strategy, could plausibly lead to an over-reliance on others and, thus, a loss of self-efficacy to negotiate the type of sex desired. This could result in non-volitional behaviors.

Existing research suggests that females are more likely to engage in non-volitional sexual risk behaviors because of inter alia gender norms, pressure from male sexual partners, and intimate partner violence (Gilmore et al., 2014). There are no published data on differences between British and EU students. However, given that people from collectivist EU countries may be at lower risk of psychological distress due to greater access to social support, it is possible that they also report lower psychological distress and less sexual risk-taking behavior (as a coping response).

\section{Hypotheses}

H1. There are significant differences between males vs. females and British vs. EU students for psychological distress, coping styles, self-harm and sexual risk behaviors. H2. Students who report self-harm exhibit more identity threat, psychological distress and frequent sexual risk behaviors than those who report no self-harm.

H3. The relationship between gender and citizenship and sexual risk behaviors will be mediated by identity threat, psychological distress, self-harm and coping styles.

\section{Ethics}

\section{Method}

The De Montfort University Faculty of Health and Life Sciences Research Ethics Committee provided ethics approval for this study (ref: 3480). 


\title{
Participants
}

A sample of 431 undergraduate students was recruited at three universities in the Midlands and Southern regions of England, UK. Approximately two thirds of the students were studying toward an undergraduate degree in psychology and received course credits in exchange for participation, and a third were recruited on campus using a convenience sampling approach and thanked for their time. Participants were aged between 18-50 $(M=21, S D=3.39)$. Please see Table 1 for full socio-demographic information.

\author{
*Insert Table 1 here*
}

\section{Measures}

\section{Identity threat}

The 6-item Identity Threat measure was adapted from the Identity Principles Scale (Murtagh, Gatersleben \& Uzzell, 2014) to measure the individual's overall perceptions of the identity principles (self-efficacy, self-esteem, continuity, and distinctiveness). Items included "I see myself as someone who has high self-esteem" (self-esteem). The items were measured on a 5-point scale (1=not true of me to $5=$ very true of me). Given that identity process theory (Breakwell, 1986) conceptualizes threat in terms of decreased levels of the identity principles, the items were reversed scored and a composite score was calculated. The scale exhibited acceptable internal reliability: $\alpha=.66$.

\section{Psychological distress}

The 18-item Brief Symptom Inventory (Derogatis, 2001) measured psychological distress over the past 7 days. Items included physical symptoms of depression, anxiety and stress, e.g. "Faintness or dizziness". Items were measured on a 5-point scale ( $1=$ not at all to $5=$ extremely). The scale exhibited excellent internal reliability: $\alpha=.93$.

\section{Coping styles}

The 20-item Coping with Identity Threat Scale (Jaspal, Lopes \& Wignall, 2020) was used to measure different styles of coping in response to identity threat. The scale includes the following five factors which reflect distinct coping styles: social engagement $\quad(\alpha=.77) ; \quad$ concealment/pretense $\quad(\alpha=.73) ; \quad$ denial $\quad(\alpha=.76)$; re-thinking/planning $(\alpha=.69)$; and self-change $(\alpha=.74)$. Items included "I tend to convince myself that it is not really happening" (denial). Items were measured on a 5 -point scale $(1=$ not at all true of me to $5=$ very true of me).

\section{Self-harm}

Self-harm was measured using the following item from the Adult Psychiatric Morbidity Survey (McManus et al., 2016): "Have you ever deliberately harmed yourself in any way but not with the intention of killing yourself?" (general). (yes=1 or no $=0$ )

\section{Volitional sexual risk behavior}

Drawing on a qualitative study of sexual risk-taking in university students (Jaspal, 2020), the following six items were created to measure the frequency of engagement in various sexual risk behaviors in the past month: (1) How often have you had vaginal sex without a condom?; (2) How often have you had anal sex without a 
condom?; (3) How often have you performed oral sex without protection (condom or dental dam)?; (4) How often have you had sex under the influence of alcohol (i.e. drunk)?; (5) How often have you had sex under the influence of drugs or substances?; and (6) How often have you had sex without a condom with someone you have just met? Items were measured on a 5 -point scale $(0=$ never to $4=$ very often). The scale exhibited acceptable internal reliability: $\alpha=.77$.

\section{Non-volitional sexual risk behavior}

Drawing on Jaspal (2020), the following five items were created to measure the frequency of engagement in various non-volitional sexual risk behaviors in the past month: (1) How often have you willingly engaged in sexual activity that you later regretted?; (2) How often have you paid for sex?; (3) How often have you been paid for sex?; (4) How often have you felt forced to engage in a sexual activity you did not want to engage in?; and (5) How often have you had your sexual partner remove a condom without consent? Items were measured on a 5 -point scale $(0=$ never to $4=$ very often). The scale exhibited acceptable internal reliability: $\alpha=.63$.

\section{Normality checks}

\section{Results}

Kolmogorov-Smirnov (K-S) tests showed that most variables were normally distributed except psychological distress $D(431)=2.11, p<.001$; volitional sexual risk behaviors $D(431)=2.01, \quad p=.001$; and non-volitional sexual risk behaviors $D(431)=4.99, p<.001$. Transformations were applied resulting in normal distributions.

\section{*Insert Table 2 here*}

\section{Descriptive statistics}

Table 2 provides a full summary of the descriptive statistics.

*Insert Table 3 here*

\section{Hypothesis 1}

Please see Table 3 for all means and standard deviations.

\section{Between-groups differences for psychological distress and coping styles}

Independent samples $t$-tests showed statistically significant differences between males vs. females for psychological distress $[t(423)=-5.346, p<.001]$ and coping by concealment/pretense $[t(423)=4.020, p<.001]$. Females exhibited much more psychological distress than males, and males were more likely to cope by concealment/pretense than females.

Further independent samples $t$-tests also showed statistically significant differences between British vs. EU students for the following variables: psychological distress $[t(395)=3.830, p<.001]$; coping by social engagement $[t(395)=-2.193$, $p=.029]$; coping by denial $[t(395)=2.657, p=.008]$; and coping by self-change $[t(395)=-2.623, p=.009]$. British students reported much more psychological distress and much more coping by denial than EU students. In contrast, EU students reported much more coping by social engagement and coping by self-change than British students. 
Between-groups differences for volitional and non-volitional sexual risk behaviors Independent samples $t$-tests showed statistically significant differences between males vs. females for volitional $[t(425)=-5.920, p<.001]$ and non-volitional $[t(425)=-4.328$, $\mathrm{p}<.001]$ sexual risk behaviors. Generally, females showed more frequent volitional and non-volitional behaviors than males.

Independent samples $t$-tests also showed statistically significant differences between British vs. EU students for volitional [t(398)=6.490, $p<.001]$ and non-volitional $[t(398)=4.980, p<.001]$ sexual risk behaviors. Generally, British students reported much more frequent volitional and non-volitional sexual risk behaviors than EU students.

\section{Effects of gender and citizenship on self-harm}

A chi-squared test showed effects of gender (males vs. females) on self-harm (no self-harm vs. self-harm $\left[\chi^{2}(2,33)=82.177, p<.001 ; P h i=.498, p<.001\right]$. More females reported self-harm $(n=137,77 \%)$ than males $(n=43,28 \%)$. In contrast, more males reported no self-harm $(n=110,72 \%)$ than females $(n=40,23 \%)$. This suggested that female university students were much more vulnerable to self-harm than males.

Another chi-squared test showed effects of citizenship (British vs. EU) on self-harm $\left[\chi^{2}(2,332)=87.820, p<.001 ; P h i=.531, p<.001\right]$. More British students reported self-harm $(n=156,74.3 \%)$ than EU students $(n=20,20 \%)$. Conversely, more EU students reported no self-harm $(n=80,80 \%)$ than British students $(n=54,26 \%)$. This suggested that British university students are more vulnerable to self-harm than EU students.

These results support hypothesis 1 . Thus, gender and citizenship were included in the model.

\section{Hypothesis 2}

\section{Differences between self-harm vs. no self-harm groups}

Independent samples $t$-tests showed statistically significant differences between those who reported self-harm vs. those who reported no self-harm for identity threat $[t(336)=-3.378, \quad p=.001]$; psychological distress $[t(333)=-8.399, p<.001)]$; and volitional $[t(332)=-5.055, p<.001]$ and non-volitional $[t(332)=-5.438, p<.001]$ sexual risk behaviors.

Students who reported self-harm exhibited much more identity threat, psychological distress, and much more frequent volitional and non-volitional behaviors than those who reported no self-harm (see Table 3).

These results support hypothesis 2 .

\section{Hypothesis 3}

Correlations

Please see Table 4 for a full set of correlations.

$$
\text { *Insert Table } 4 \text { here* }
$$

\section{Multiple stepwise regression models}

Multiple stepwise regressions were conducted to examine which coping styles predict the variance of volitional and non-volitional sexual risk behaviors. Hence, the variables of coping by social engagement; concealment/ pretense; denial; re-thinking/planning; and self-change were inserted as predictors and the variables of 
volitional and non-volitional sexual risk behaviors were inserted as dependent variables.

The first regression model was statistically significant for volitional sexual risk behaviors $\left[F(2,428)=5.714, p=.004 ; R^{2}=.026\right]$. Of all predictors, only denial with a $\beta=.16$, S.E. $=.010,95 \%$ CIs $(.024, .065)(t=3.064, p=.002)$; and re-thinking/planning with a $\beta=-.13$, S.E. $=.008,95 \%$ CIs $(-.055,-.023)(t=-2.443, p=.015)$ had significant effects on the variance of volitional sexual risk behaviors.

The second regression model was statistically significant for non-volitional sexual risk behaviors $\left[F(2,428)=13.748, p<.001 ; R^{2}=.061\right]$. Of all the predictors, only denial with a $\beta=.20$, S.E. $=.004,95 \%$ CIs $(.012, .029)(t=4.266, p<.001)$; and social engagement with a $\beta=.12$ S.E. $=.004,95 \%$ CIs $(.010, .024)(t=2.591, p=.010)$ had significant effects on the variance of non-volitional sexual risk behaviors.

\section{Structural equation model}

Since there were significant effects of gender (dummy coded as $0=$ male vs. $1=$ female) and citizenship (dummy coded as $0=$ British vs. $1=E U$ ) on volitional and non-volitional sexual risk behaviors, these variables were inserted in the structural equation model as main predictors, followed by the following mediation variables: identity threat, psychological distress and self-harm, and coping by re-thinking/planning and with social engagement. Volitional and non-volitional sexual risk behaviors were inserted as dependent variables (see Figure 2).

Model fit was acceptable with a Root Mean Square Error of Approximation (RSMEA) of .06 and a Tucker-Lewis Index (TLI)>.95 and a Confirmatory Factor Index $(\mathrm{CFI})>.80$.

First, the model showed that gender and citizenship had effects on the dependent variable of volitional sexual risk behaviors $[\beta=.13$, S.E. $=.076, p=.008$ for gender; $\beta=-.17$, S.E. $=.063, p<.001$ for citizenship]. Citizenship also had a direct effect on the variance of non-volitional sexual risk behaviors with a $\beta=-.14$, S.E. $=.028, p=.001$.

There were mediation effects. First, gender had direct effects on both psychological distress and self-harm $[\beta=.29$, S.E. $=2.275, \quad p<.001$ and $\beta=.32$ S.E. $=0.46, p<.001$, respectively].

Citizenship had a direct effect on self-harm with a $\beta=-.30$, S.E. $=.038, p<.001$. Self-harm then impacted on the variance of identity threat with a $\beta=.49$, S.E. $=.144$, $p<.001$. Identity threat in turn impacted on the variances of both self-harm and psychological distress with a $\beta=.38$, S.E. $=.055, p<.001$ and $\beta=.08$, S.E. $=8.980$, $p=.049$.

Psychological distress then impacted on the variance of coping by re-thinking/planning with a $\beta=.31$, S.E. $=.012, p<.001$, which in turn impacted on the variance of volitional sexual risk behaviors with a $\beta=-.11$, S.E. $=.010, p=.022$.

Furthermore, both psychological distress and self-harm impacted on the variance of coping by social engagement with a $\beta=.12$, S.E. $=.013, p=.018$ and a $\beta=-.12$, S.E. $=.428, p=.041$. Coping by social engagement in turn impacted on the variance of non-volitional sexual risk behaviors with a $\beta=.14$, S.E. $=.005, p=.001$.

It is noteworthy that psychological distress also had statistically significant direct effects on the variance of both volitional and non-volitional sexual risk behaviors with $\beta=.16$, S.E. $=.003, p=.001$ and $\beta=.32$, S.E. $=.001, p<.001$, respectively. Overall, the results support hypothesis 3 . 


\section{Discussion}

This study focused on the social psychological predictors of volitional and non-volitional sexual risk behaviors in a sample of British and EU undergraduate students at British universities. This complements existing research into other risk factors (Gardner \& Steinberg, 2005; Goundry, Finlay \& Llewellyn, 2013; Milhausen et al., 2013).

Although reported levels of sexual risk-taking were low in this particular sample, the results indicated two distinct pathways for the different types of sexual risk behavior. One involved coping by re-thinking/planning, which was associated with volitional sexual risk behaviors, and the other involved coping by social engagement which in turn was associated with non-volitional sexual risk behaviors. Gender and citizenship are important variables - females and British citizens appeared to be more vulnerable to poor sexual health. The results supported the hypotheses associated with the Health Adversity Risk Model that identity threat and psychological distress are related to increased engagement in sexual risk-taking behavior.

\section{Gender and risk}

Female students exhibited higher levels of psychological distress, greater vulnerability to self-harm but a lower preference for coping with identity threat by concealment/ pretense than male students. Moreover, they reported more frequent volitional and non-volitional sexual risk behaviors than males. This is consistent with existing research indicating that female students experience multiple situational stressors which can undermine their psychological wellbeing (Stallman, 2010). Although not the focus of this study, specific situational stressors known to be prevalent among female students include gender inequalities, body image issues, and social pressures to 'fit in' (Rayle \& Chung, 2007; Stallman, 2010). Moreover, self-harm may be more prevalent among female students than among male students, because they have been found to experience much higher exposure to the situational stressors known to be associated with this type of coping, such as physical abuse, sexual abuse, neglect and childhood adversity (Gratz, Conrad \& Roemer, 2002). Our data showed that self-harm itself appears to be associated with both identity threat and psychological distress, suggesting that it may constitute a response to, and reinforcement of, psychological adversity.

Moreover, females were more likely than males to engage in both types of sexual risk behavior, which can be attributed to several factors. First, hormonal contraception may be perceived to obviate the need for condoms during sex when sexual health is construed as avoiding pregnancy. Second, there is evidence of perceived sexual coercion among females, who may feel pressurized by their male partners to engage in sexual activities (including risk behaviors) that they do not desire (Chanakira et al, 2015). Although not all of these variables were measured in this study, they may explain the greater proneness to risk behaviors among females.

\section{Citizenship and risk}

British students exhibited higher psychological distress and a higher preference for coping with identity threat by denial, and greater vulnerability to self-harm than EU students who, conversely, reported a stronger preference for coping by social engagement and by self-change than their British counterparts. Moreover, British students reported more frequent volitional and non-volitional sexual risk behaviors than EU students. These results could be attributed to cultural differences between British and EU students (Vignoles et al., 2018). Although the EU is of course very 
diverse, the EU students in this sample were from culturally and religiously conservative countries with a socially hierarchical/ collectivist cultural orientation (Hofstede, 2008), which emphasizes commitment to others over self-interest (Vignoles et al., 2018). In collectivist cultures, the social group is the primary focus of identity for individuals and, thus, it is easy to see why a social engagement coping style may be more readily adopted than in less collectivist countries, such as the UK. Furthermore, in view of the primacy of the social group over the individual, it is understandable that the self-change coping style (which consists of one's willingness to change elements of one's identity) is more readily adopted by EU citizens. These are generally considered to be adaptive coping strategies, which may be protective against self-harm.

The observed difference in rates of sexual risk-taking may be also be attributed to cultural differences. In British society, sex arguably remains a taboo topic. For instance, in a multi-country survey on morality (Pew Research Centre, 2014), a larger proportion of the British respondents (38\%) viewed sex between unmarried adults as morally unacceptable than that of EU respondents. Moreover, British students describe their difficulties in discussing their sexual behavior with peers due to the perceived stigma of casual sex (Chanakira et al., 2015). Conversely, in many EU countries, more liberal attitudes toward, and open discussion about, sex may lead individuals to develop a more comfortable relationship with their sexuality (e.g. Rostosky, Dekhtyar, Cupp \& Anderman, 2008).

\section{The pathways toward sexual risk}

The structural equation model outlines the possible pathways toward different types of sexual risk. The relationship between gender (male vs. female) and citizenship (British vs. EU) and volitional and non-volitional sexual risk behaviors was mediated by the identity threat, psychological distress, self-harm, and coping styles variables, which highlighted two distinct pathways toward sexual risk behavior.

Female and British students were more likely to engage in self-harm (a psychopathological variable) than male and EU students, respectively (Gratz, Conrad \& Roemer, 2002). Moreover, female students were more likely to experience psychological distress than male students (Stallman, 2010). Psychological distress had a direct impact on both forms of sexual risk behavior, suggesting that this is a predictor of sexual risk-taking (DiClemente et al., 2001). There was a reciprocal relationship between self-harm and identity threat in that both variables impacted on one another. On the one hand, this could be attributed to the decreased problem-solving skills that tend to be associated with self-harm (Slee et al., 2008), which in turn could increase one's proclivity to identity threat in response to potentially threatening situations to which a person with more advanced problem-solving skills might ordinarily react less adversely. On the other hand, self-harm may constitute a response to identity threat (especially hyper-threat involving multiple principles) because this represents acute life stress (O'Connor, Rasmussen \& Hawton, 2010). Moreover, the model demonstrated that identity threat was associated with psychological distress (Breakwell, 1986; Assi, Maatouk \& Jaspal, 2020).

The model exhibited an important role of coping style in sexual risk-taking. The relationship between psychological distress and volitional sexual risk behaviors was mediated by the re-thinking/planning coping style, while the relationship between psychological distress and non-volitional sexual risk behaviors was mediated by the 
social engagement coping style. These findings shed light on the possible implications of coping style for sexual risk.

More specifically, the re-thinking/planning coping style, which includes strategies such as re-conceptualization and re-thinking one's priorities, reflects calculation, self-awareness, and agency. Though generally an adaptive strategy for coping, it does not appear to be protective against sexual risk-taking - rather, it may change the nature of the risk-taking in that it appears to be more associated with volitional sexual risk behaviors.

Conversely, psychological distress was associated with non-volitional sexual risk behaviors through the social engagement coping style, which includes strategies that involve engagement with other people. When individuals come to see themselves principally in terms of their group memberships, that is, when their social identities are salient, their individuality (including their individual personality traits, preferences and personal volition) is attenuated vis-à-vis their social group membership (Pehrson $\&$ Reicher, 2014). When their social identities are salient, individuals may experience reduced motivation to assert personal agency, including in relation to their sexual encounters. Despite being an adaptive coping style, social engagement does not appear to reduce risk either but may be associated with engagement in non-volitional sexual risk behaviors.

\section{Limitations}

This study has several limitations which should be addressed in future research. First, the participant sample was not ethnically diverse and most participants were either White British or White Other, which precluded comparisons with students of ethnic minority background. In view of sexual health inequalities faced by ethnic minorities (Fish, Papaloukas, Jaspal \& Williamson, 2016), it is important to examine risk-taking in this population in future research. Second, the EU consists of twenty-seven member states and there is much cultural variation. Students from three countries with some cultural overlap participated in this study. In future research, EU students from other countries should also be recruited. Third, it would be beneficial to replicate this study in a sample of lesbian, gay, bisexual, trans and questioning (LGBTQ) university students given that these groups were under-represented in this sample. Fourth, the cross-sectional design of the study prevents claims about causality. It would be advantageous to test causality using both experimental and longitudinal data in the context of identity threat and sexual risk-taking. Fifth, although there are advantages in measuring identity threat in general, future research might attempt to focus on the first 'stage' of the model, namely the specific social stressors which are faced by students and which may lead to identity threat. In this study, it is noted that multiple situational stressors exist for university students but specific stressors were not measured.

\section{Conclusions}

Consistent with the Health Adversity Risk Model, this study shows that decreased psychological wellbeing is associated with engagement in sexual risk-taking. Though generally adaptive, the coping styles of re-thinking/planning and social engagement are not protective against sexual risk-taking but rather are associated with distinct types of sexual risk-taking. When designing effective sexual health promotion interventions, it is important to acknowledge the role of social and cultural norms, which may influence identity threat, psychological distress, coping styles and risk-taking behaviors among university students from distinct backgrounds. This 
study shows that social psychological factors, namely identity, affect and coping style, are inextricably entwined with sexual behavior and, thus, sexual health outcomes.

\section{References}

Assi, M., Maatouk, I., \& Jaspal, R. (2020). Psychological distress and self-harm in a religiously diverse sample of university students in Lebanon. Mental Health, Religion \& Culture, 23(7), 591-605. https://doi.org/10.1080/13674676.2020.1788524

Binfet, J., \& Passmore, H. (2016). Hounds and homesickness: The effects of an animal-assisted therapeutic intervention for first-year university students. Anthrozoös, 29(3), 441-454. https://doi.org/10.1080/08927936.2016.1181364

Breakwell, G.M. (1986). Coping with threatened identities. London: Methuen. Chanakira, E., Goyder, E. C., Freeman, J. V., O' Cathain, A., Kinghorn, G., \& Jakubovic, M. (2015). Social and psychosocial factors associated with high-risk sexual behavior among university students in the United Kingdom: a web-survey. International Journal of STD \& AIDS, 26(6), 369-378.

https://doi.org/10.1177/0956462414538950

Chanakira, E., O'Cathain, A., Goyder, E. C. \& Freeman, J. V. (2014). Factors

perceived to influence risky sexual behaviors among university students in the United Kingdom: a qualitative telephone interview study. BMC Public Health, 14(1055). https://doi.org/10.1186/1471-2458-14-1055

Choi, H., Bowleg, L. \& Neilands, T. B. (2011). The effects of sexism, psychological distress, and difficult sexual situations on US women's sexual risk behaviors. AIDS Education \& Prevention, 23(5), 397-411. https://doi.org/10.1521/aeap.2011.23.5.397 Collado, A., Johnson, P. S., Loya, J. M., Johnson, M. W. \& Yi, R. (2017). Discounting of condom-protected sex as a measure of high risk for sexually transmitted infection among college students. Archives of Sexual Behavior, 46(7), 2187-2195.

https://doi.org/10.1007/s10508-016-0836-x

Dariotis, J. K., \& Chen, F. R. (2020) Stress coping strategies as mediators: Toward a better understanding of sexual, substance, and delinquent behavior-related risk-taking among transition-aged youth. Deviant Behavior.

https://doi.org/10.1080/01639625.2020.1796210

Department of Education (2017). Participation rates in higher education: academic years 2006/2007 - 2015/2016 (Provisional).

https://assets.publishing.service.gov.uk/government/uploads/system/uploads/attachme nt data/file/648165/HEIPR_PUBLICATION_2015-16.pdf

Derogatis, L. R. (2001). Brief Symptom Inventory (BSI)-18: Administration, scoring and procedures manual. Minneapolis, MN: NCS Pearson.

https://doi.org/10.1037/t07502-000

DiClemente, R. J., Wingood, G. M., Crosby, R. A., Sionean, C., Brown, L. K., Rothbaum, B., Zimand, E., Cobb, B. K., Harrington, K., \& Davies, S. (2001). A prospective study of psychological distress and sexual risk behavior among black adolescent females. Pediatrics, 108(5), E85. https://doi.org/10.1542/peds.108.5.e85 Fish, J., Papaloukas, P., Jaspal, R., \& Williamson, I. (2016). Equality in sexual health promotion: a systematic review of effective interventions for black and minority ethnic men who have sex with men. BMC Public Health, 16(810).

https://doi.org/10.1186/s12889-016-3418-X

French, B. H., Tilghman, J. D., \& Malebranche, D. A. (2015). Sexual coercion and psychosocial correlates among diverse males. Psychology of Men \& Masculinity, 16(1), 42-53. https://doi.org/10.1037/a0035915 
Gardner, M., \& Steinberg, L. (2005). Peer influence on risk taking, risk preference, and risky decision making in adolescence and adulthood: An experimental study. Developmental Psychology, 41(4), 625-635. https://doi.org/10.1037/0012-1649.41.4.625 Gilmore, A. K., Schacht, R. L., George, W. H., Davis, K. C., Norris, J., \& Heiman, J. R. (2014). Verbal sexual coercion experiences, sexual risk, and substance use in women. Journal of Aggression, Maltreatment \& Trauma, 23(7), 725-739. https://doi.org/10.1080/10926771.2014.933462

Goundry, A. L. Finlay, E. R. \& Llewellyn, C. D. (2013). Talking about links between sexually transmitted infections and infertility with college and university students from SE England, UK: A qualitative study. BMC Reproductive Health, 10(47). https://doi.org/10.1186/1742-4755-10-47

Gratz, K. L., Conrad, S. D. \& Roemer, L. (2002). Risk factors for deliberate self-harm among college students. American Journal of Orthopsychiatry, 72(1), 128-40. https://doi.org/10.1037/0002-9432.72.1.128 Hofstede, G. (2008). Geert Hofstede Cultural Dimensions [Online]. Available from http://www.geert-hofstede.com. Hubble, S. \& Bolton, P. (2019). International and EU students in higher education in the UK FAQs. Briefing Paper, Number CBP 7976, 26 September 2019.

https://researchbriefings.parliament.uk/ResearchBriefing/Summary/CBP-7976\#fullrep $\underline{\text { ort }}$

Jaspal, R. (2020). Sexual health perceptions among first-year students at a British university. American Journal of Sexuality Education, 15(2), 158-179. https://doi.org/10.1080/15546128.2019.1701597

Jaspal, R., \& Bayley, J. (2020). HIV and gay men: Clinical, social and psychological aspects. London: Palgrave. https://doi.org/10.1007/978-981-15-7226-5

Jaspal, R., Lopes, B., \& Wignall, L. (2020). The Coping with Identity Threat Scale: development and validation in a university student sample. Identity: An International Journal of Theory and Research, 20(4), 225-238.

https://doi.org/10.1080/15283488.2020.1808469

McManus, S., Hassiotis, A., Jenkins, R., Dennis, M., Aznar, C., \& Appleby, L. (2016). Suicidal thoughts, suicide attempts and self-harm In S. McManus, P. Bebbington, R. Jenkins \& T. Brugha (eds.), Mental health and wellbeing in England: Adult Psychiatric Morbidity Survey 2014. Leeds: NHS Digital.

https://assets.publishing.service.gov.uk/government/uploads/system/uploads/attachme nt_data/file/556596/apms-2014-full-rpt.pdf

Milhausen, R. R., McKay, A., Graham, C. A., Crosby, R. A., Yarber, W. L., \& Sanders, S. A. (2014). Prevalence and predictors of condom use in a national sample of Canadian university students. The Canadian Journal of Human Sexuality, 22(3), 142-151. https://doi.org/10.3138/cjhs. 2316

Morgan, T., Ness, D., \& Robinson, M. (2003). Students' help-seeking behaviors by gender, racial background, and student status. Canadian Journal of Counselling, 37(2), 151-66.

Murtagh, N., Gatersleben, B., \& Uzzell, D. (2014). Identity threat and resistance to change: evidence and implications from transport-related behavior. In R. Jaspal \& G.M. Breakwell (eds), Identity process theory: Identity, social action and social change (pp. 335-356). Cambridge: Cambridge University Press.

https://doi.org/10.1017/CBO9781139136983.021

O' Connor, R. C., Rasmussen, S., \& Hawton, K. (2010). Predicting depression, anxiety and self-harm in adolescents: The role of perfectionism and acute life stress. 
Behavior Research and Therapy, 48(1), 52-59.

https://doi.org/10.1016/j.brat.2009.09.008

Pew Research Centre (2014). Global views on morality: Compare values across 40 countries.

https://www.pewresearch.org/global/2014/04/15/global-morality/table/premarital-sex Pehrson, S. D. \& Reicher, S. D. (2014). On the meaning, validity and importance of the distinction between personal and social identity: a social identity perspective on Identity Process Theory. In R. Jaspal \& G.M. Breakwell (eds), Identity process theory: Identity, social action and social change (pp. 97-117). Cambridge: Cambridge University Press. https://doi.org/10.1017/CBO9781139136983.009

Public Health England (2018). An STI is diagnosed in a young person every 4 minutes in England

https://www.gov.uk/government/news/an-sti-is-diagnosed-in-a-young-person-every-4minutes-in-england

Public Health England (2019). Sexually transmitted infections and screening for chlamydia in England, 2018. Health Protection Report, 13(19)

https://assets.publishing.service.gov.uk/government/uploads/system/uploads/attachme nt_data/file/806118/hpr1919 stis-ncsp_ann18.pdf

Rayle, A. D., \& Chung, K. (2007). Revisiting first-year college students' mattering: social support, academic stress, and the mattering experience. Journal of College

Student Retention: Research, Theory \& Practice, 9(1), 21-37.

https://doi.org/10.2190/X126-5606-4G36-8132

Rostosky, S. S., Dekhtyar, O., Cupp, P. L., \& Anderman, E.M. (2008). Sexual

self-concept and sexual self-efficacy in adolescents: a possible clue to promoting sexual health? Journal of Sex Research, 45(3), 277-286.

https://doi.org/10.1080/00224490802204480

Senn, T. E., \& Carey, M. P. (2010). Child maltreatment and women's adult sexual risk behavior: childhood sexual abuse as a unique risk factor. Child Maltreatment, 15(4), 324-35. https://doi.org/10.1177/1077559510381112

Slee, N., Garnefski, N., van der Leeden, R., Arensman, E., \& Spinhoven, P. (2008).

Cognitive-behavioral intervention for self-harm: randomised controlled trial. The

British Journal of Psychiatry, 192(3), 202-211.

https://doi.org/10.1192/bjp.bp.107.037564

Stallman, H. M. (2010). Psychological distress in university students: A comparison with general population data. Australian Psychologist, 45(4), 249-57.

https://doi.org/10.1080/00050067.2010.482109

Vignoles, V. L., Smith, P. B., Becker, M., \& Easterbrook, M. J. (2018). In search of a pan-European culture: European values, beliefs, and models of self-hood in global perspective. Journal of Cross-Cultural Psychology, 49(6), 868-887.

https://doi.org/10.1177/0022022117738751 


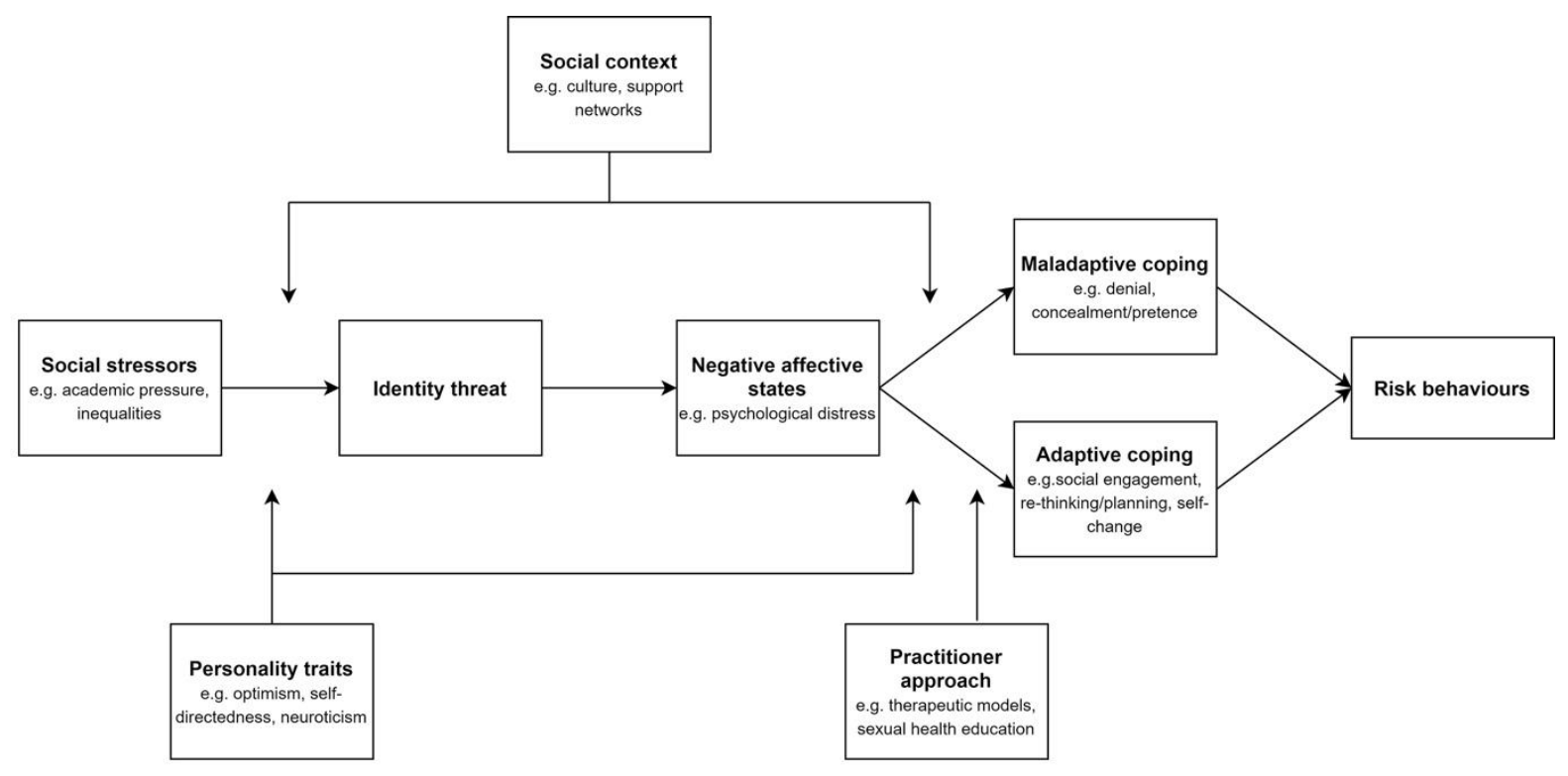

Figure 1: Health Adversity Risk Model

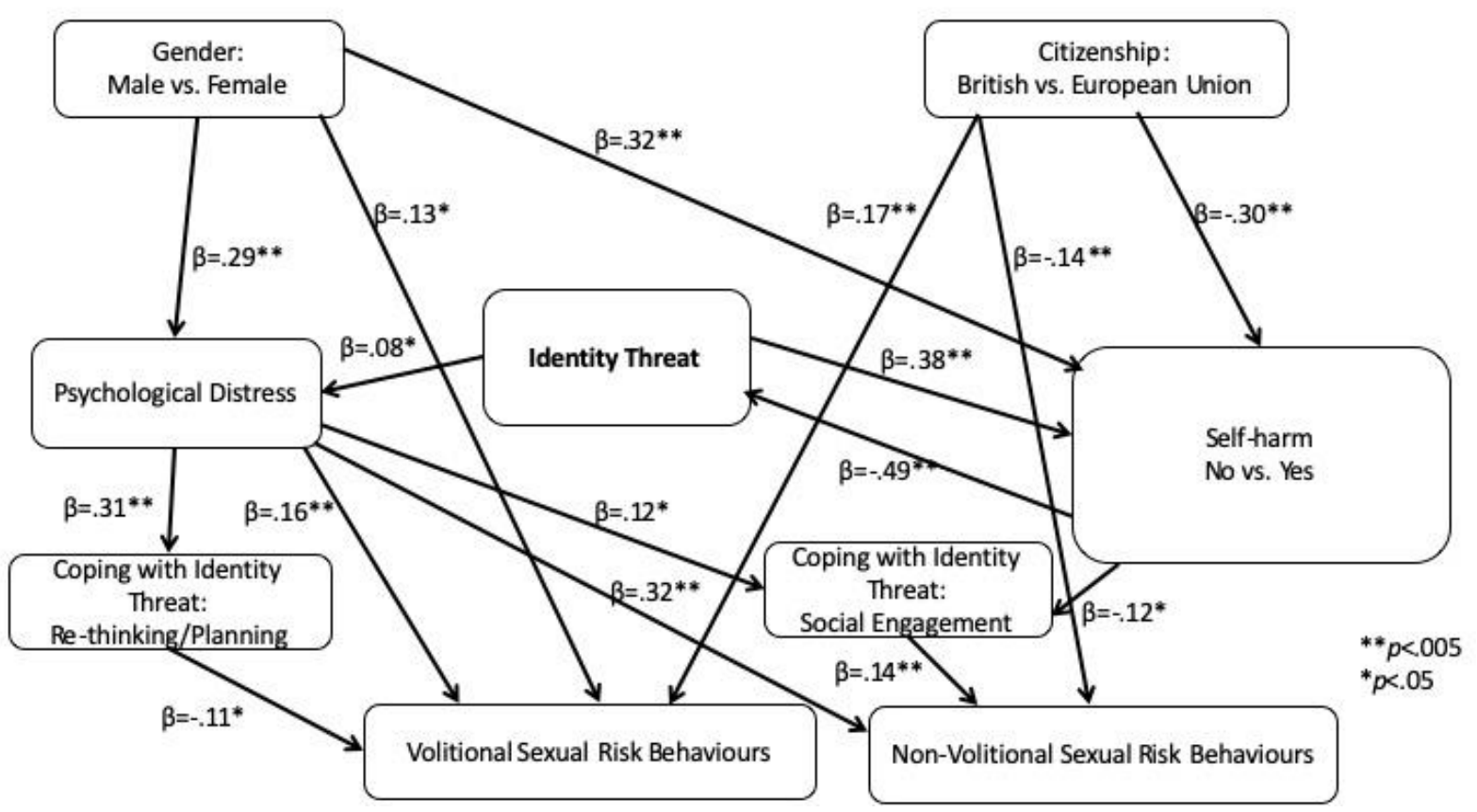

Figure 2: Structural equation model predicting volitional and non-volitional sexual risk behaviours 
Table 1. Socio-demographic characteristics of the participant sample

\begin{tabular}{|c|c|c|c|c|c|c|c|c|c|c|c|c|c|}
\hline & Mean & $S D$ & Minimum & Maximum & & & & & & & & & \\
\hline Age & 21 & .31 & 18 & 50 & & & & & & & & & \\
\hline Gender & $\begin{array}{l}\text { Males } \\
N=167 \\
(34 \%)\end{array}$ & $\begin{array}{l}\text { Females } \\
N=262 \\
(61 \%)\end{array}$ & $\begin{array}{l}\text { Non-Binary } \\
N=2 \\
(.5 \%)\end{array}$ & & & & & & & & & & \\
\hline \multirow{2}{*}{$\begin{array}{l}\text { Sexual } \\
\text { orientation }\end{array}$} & Heterosexu & Gay & Lesbian & Bisexual & Asexual & Other & & & & & & & \\
\hline & $\begin{array}{l}N=335 \\
(78 \%)\end{array}$ & $\begin{array}{l}N=12 \\
(3 \%)\end{array}$ & $\begin{array}{l}N=4 \\
(.9 \%)\end{array}$ & $\begin{array}{l}N=70 \\
(16 \%)\end{array}$ & $\begin{array}{l}N=3 \\
(.7 \%)\end{array}$ & $\begin{array}{l}N=7 \\
(2 \%)\end{array}$ & & & & & & & \\
\hline \multirow[t]{2}{*}{ Citizenship } & British & $E U$ & Polish & Greece & Cyprus & $\begin{array}{l}\text { Non-EU } \\
\text { Internat } \\
\text { ional }\end{array}$ & & & & & & & \\
\hline & $\begin{array}{l}N=295 \\
(69 \%)\end{array}$ & $\begin{array}{l}N=106 \\
(25 \%)\end{array}$ & $N=63$ & $\mathrm{~N}=27$ & $\mathrm{~N}=16$ & $\begin{array}{l}N=24 \\
(6 \%)\end{array}$ & & & & & & & \\
\hline \multirow[t]{2}{*}{ Religion } & $\begin{array}{l}\text { No } \\
\text { Religion }\end{array}$ & Christian & Muslim & Hindu & Sikh & Other & Buddhist & Jewish & & & & & \\
\hline & $\begin{array}{l}N=305 \\
(71 \%)\end{array}$ & $\begin{array}{l}N=68 \\
(16 \%)\end{array}$ & $\begin{array}{l}N=15 \\
(4 \%)\end{array}$ & $N=13(3 \%)$ & $\begin{array}{l}N=12 \\
(3 \%)\end{array}$ & $\begin{array}{l}N=9 \\
(2 \%)\end{array}$ & $\begin{array}{l}N=7 \\
(1.6 \%)\end{array}$ & $\begin{array}{l}N=2 \\
(.5 \%)\end{array}$ & & & & & \\
\hline \multirow[t]{2}{*}{ Ethnicity } & $\begin{array}{l}\text { White } \\
\text { British }\end{array}$ & White Other & African & Indian & $\begin{array}{l}\text { Pakista } \\
n i\end{array}$ & $\begin{array}{l}\text { Other } \\
\text { Asian }\end{array}$ & $\begin{array}{l}\text { White and } \\
\text { Asian }\end{array}$ & $\begin{array}{l}\text { Other } \\
\text { Mixed }\end{array}$ & Other & $\begin{array}{l}\text { Caribb } \\
\text { ean }\end{array}$ & $\begin{array}{l}\text { Other } \\
\text { Black }\end{array}$ & $\begin{array}{l}\text { White and } \\
\text { Black African }\end{array}$ & $\begin{array}{l}\text { Banglade } \\
\text { shi }\end{array}$ \\
\hline & $\begin{array}{l}N=237 \\
(35 \%)\end{array}$ & $\begin{array}{l}N=95 \\
(22 \%)\end{array}$ & $\begin{array}{l}N=16 \\
(3.7 \%)\end{array}$ & $N=13(3 \%)$ & $\begin{array}{l}N=13 \\
(3 \%)\end{array}$ & $\begin{array}{l}N=11 \\
(2.6 \%)\end{array}$ & $\begin{array}{l}N=9 \\
(2 \%)\end{array}$ & $\begin{array}{l}N=9 \\
(2 \%)\end{array}$ & $\begin{array}{l}N=7 \\
(1.6 \%)\end{array}$ & $\begin{array}{l}N=6 \\
(1.4 \%)\end{array}$ & $\begin{array}{l}N=4 \\
(.9 \%)\end{array}$ & $\begin{array}{l}N=4 \\
(.9 \%)\end{array}$ & $\begin{array}{l}N=2 \\
(.5 \%)\end{array}$ \\
\hline \multirow[t]{2}{*}{$\begin{array}{l}\text { Relationship } \\
\text { status }\end{array}$} & Single & Monogamous & Engaged & Open & $\begin{array}{l}\text { Marrie } \\
d\end{array}$ & $\begin{array}{l}\text { Civil } \\
\text { partners } \\
\text { hip }\end{array}$ & & & & & & & \\
\hline & $\begin{array}{l}N=245 \\
(56.8 \%)\end{array}$ & $\begin{array}{l}N=153 \\
(35.7 \%)\end{array}$ & $\begin{array}{l}N=13 \\
(3 \%)\end{array}$ & $N=7(1.6 \%)$ & $\begin{array}{l}N=6 \\
(1.4 \%)\end{array}$ & $\begin{array}{l}N=6 \\
(1.4 \%)\end{array}$ & & & & & & & \\
\hline
\end{tabular}


Table 2. Descriptive statistics for the continuous and categorical variables of this study

Continuous Variables $(n=431)$

Volitional Sexual Risk Behaviour

Non-Volitional Sexual Risk Behaviour

Identity Threat

Social Engagement Coping Style

Concealment/Pretence Coping Style

Denial Coping Style

Re-thinking/Planning Coping Style

Self-Change Coping Style

Psychological Distress

\section{Self-harm: $N=338$}

$0=$ No self-harm

$1=$ Self-harm

$\begin{array}{llll}\text { Mean } & \text { SD } & \text { Minimum } & \text { Maximum } \\ 1.11 & .85 & 0 & 3.50 \\ .31 & .43 & 0 & 2.60 \\ 3.23 & .68 & 1.3 & 5 \\ 10.72 & 3.59 & 4 & 20 \\ 10.33 & 3.63 & 4 & 20 \\ 12.03 & 3.86 & 5 & 24 \\ 16.03 & 3.78 & 5 & 25 \\ 5.16 & 2.00 & 2 & 10 \\ 20.81 & 14.92 & 18 & 71\end{array}$

aximum

2.60 
Table 3. Means, standard deviations, effect sizes and 95\% confidence intervals for the between groups' differences (gender, citizenship, and self-harm) for the key

\begin{tabular}{|c|c|c|c|c|c|c|}
\hline & $\begin{array}{l}\text { Female } \\
N=262\end{array}$ & & $\begin{array}{l}\text { Males } \\
N=167\end{array}$ & & Cohen's d & $95 \% \mathrm{CI}$ \\
\hline \multirow{2}{*}{ Psychological Distress } & $M$ & $S D$ & $M$ & $S D$ & 0.5 & $-10.431,-4.583$ \\
\hline & 23.54 & 13.99 & 16.00 & 14.46 & & \\
\hline \multirow[t]{2}{*}{ Concealment/Pretence Coping Style } & $M$ & $S D$ & $M$ & $S D$ & 0.4 & $.7546,2.1342$ \\
\hline & 9.75 & 3.45 & 11.19 & 3.50 & & \\
\hline \multirow{2}{*}{ Volitional Sexual Risk Behaviour } & $M$ & $S D$ & $M$ & $S D$ & 0.6 & $-.5912,-.3027$ \\
\hline & 1.30 & .79 & .85 & .71 & & \\
\hline \multirow[t]{3}{*}{ Non-Volitional Sexual Risk Behaviour } & $M$ & $S D$ & $M$ & $S D$ & 0.4 & $-.2186,-.0835$ \\
\hline & .38 & .36 & .23 & .34 & & \\
\hline & $\begin{array}{l}\text { British } \\
N=295\end{array}$ & & $\begin{array}{l}\text { EU Citizens } \\
N=106\end{array}$ & & & \\
\hline \multirow[t]{2}{*}{ Psychological distress } & $M$ & $S D$ & $M$ & $S D$ & 0.4 & $3.0665,9.588$ \\
\hline & 22.28 & 14.70 & 16.04 & 13.38 & & \\
\hline \multirow{2}{*}{ Social Engagement Coping Style } & $M$ & $S D$ & $M$ & $S D$ & 0.2 & $-1.563,-.0649$ \\
\hline & 10.52 & 3.60 & 11.33 & 3.09 & & \\
\hline \multirow{2}{*}{ Denial Coping Style } & $M$ & $S D$ & $M$ & $S D$ & 0.3 & $3.188,1.964$ \\
\hline & 12.19 & 3.81 & 11.17 & 3.45 & & \\
\hline \multirow[t]{2}{*}{ Self-Change Coping Style } & $M$ & $S D$ & $M$ & $S D$ & 0.3 & $-.9593, .1108$ \\
\hline & 5.00 & 1.90 & 5.57 & 1.18 & & \\
\hline \multirow[t]{2}{*}{ Volitional Sexual Risk Behaviour } & $M$ & $S D$ & $M$ & $S D$ & 0.7 & $.347, .651$ \\
\hline & 1.27 & .81 & .77 & .61 & & \\
\hline \multirow{4}{*}{ Non-Volitional Sexual Risk Behaviour } & $M$ & $S D$ & $M$ & $S D$ & 0.5 & $.1066, .2505$ \\
\hline & .37 & .36 & .19 & .30 & & \\
\hline & No Self & & Self-Harm & & & \\
\hline & $N=153$ & & $N=185$ & & & \\
\hline \multirow[t]{2}{*}{ Psychological Distress } & $M$ & $S D$ & $M$ & $S D$ & 0.9 & $-15.446,-9.374$ \\
\hline & 14.56 & 13.40 & 27.00 & 3.58 & & \\
\hline \multirow[t]{2}{*}{ Identity Threat } & $M$ & $S D$ & $M$ & $S D$ & 0.4 & $-3.902,-.1041$ \\
\hline & 3.13 & .67 & 3.37 & .67 & & \\
\hline \multirow[t]{2}{*}{ Volitional Sexual Risk Behaviour } & $M$ & $S D$ & $M$ & $S D$ & 0.5 & $-.5997, .-2690$ \\
\hline & .88 & .69 & 1.31 & .88 & & \\
\hline \multirow[t]{2}{*}{ Non-Volitional Sexual Risk Behaviour } & $M$ & $S D$ & $M$ & $S D$ & 0.6 & $-.2821,-.1252$ \\
\hline & .22 & .31 & .43 & .38 & & \\
\hline Denial Coping Style & $M$ & $S D$ & $M$ & $S D$ & 0.3 & $-2.075, .4091$ \\
\hline
\end{tabular}


Table 4. Correlations between the key variables of this study

\begin{tabular}{|c|c|c|c|c|c|c|c|c|c|c|}
\hline & VSRB & NVSRB & $\begin{array}{l}\text { Identity } \\
\text { threat }\end{array}$ & $\begin{array}{l}\text { Self-har } \\
\mathrm{m}\end{array}$ & $\begin{array}{l}\text { Psychol } \\
\text { ogical } \\
\text { distress }\end{array}$ & $\begin{array}{l}\text { Social } \\
\text { engage } \\
\text { ment }\end{array}$ & $\begin{array}{l}\text { Conceal } \\
\text { ment/pr } \\
\text { etence }\end{array}$ & Denial & $\begin{array}{l}\text { Re-think } \\
\text { ing/plan } \\
\text { ning }\end{array}$ & Self-change \\
\hline VSRB & & $.47 * *$ & -.00 & $.26^{* *+}$ & $.14^{* *}$ & .02 & -.06 & $.09^{*}$ & -.07 & .01 \\
\hline NVSRB & $.47^{* *}$ & & .06 & $.30 * *+$ & $.33^{* *}$ & $.17^{* *}$ & $.13^{* *}$ & $.23^{* *}$ & $.11 *$ & $.13^{* *}$ \\
\hline $\begin{array}{l}\text { Identity } \\
\text { threat }\end{array}$ & -.00 & .06 & & $.19 * *+$ & $.33^{* *}$ & $-.19 * *$ & $.21^{* *}$ & .08 & .01 & -.04 \\
\hline $\begin{array}{l}\text { Self-harm } \\
\text { Psychologi } \\
\text { cal distress }\end{array}$ & $\begin{array}{l}.26^{* *+} \\
.14^{* *}\end{array}$ & $\begin{array}{l}.30^{* *+} \\
.33^{* *}\end{array}$ & $\begin{array}{l}.19^{* *+} \\
.33^{* *}\end{array}$ & $.43 * *+$ & $.43^{* *+}$ & $\begin{array}{l}-.095+ \\
.07\end{array}$ & $\begin{array}{l}.10+ \\
.40^{* *}\end{array}$ & $\begin{array}{l}.17^{* *+} \\
.40^{* *}\end{array}$ & $\begin{array}{l}.17^{* *+} \\
.29^{* *}\end{array}$ & $\begin{array}{l}-.03+ \\
.12^{*}\end{array}$ \\
\hline $\begin{array}{l}\text { Social } \\
\text { engagemen } \\
\text { t }\end{array}$ & .02 & $.17 * *$ & $-.19 * *$ & $-.095+$ & .07 & & .08 & $.11 *$ & $.30^{* *}$ & $.31 * *$ \\
\hline $\begin{array}{l}\text { Concealme } \\
\text { nt/pretence }\end{array}$ & -.06 & $.13^{* *}$ & $.21^{* *}$ & $.10+$ & $.40^{* *}$ & .08 & & $.46^{* *}$ & $.33 * *$ & $.24 * *$ \\
\hline Denial & $.09 *$ & $.23 * *$ & .08 & $.17^{* *+}$ & $.40^{* *}$ & $.11 *$ & $.46^{* *}$ & & $.32 * *$ & $.34 * *$ \\
\hline $\begin{array}{l}\text { Re-thinkin } \\
\text { g/planning }\end{array}$ & -.07 & $.11 *$ & .01 & $.17 * *+$ & $.29 * *$ & $.30 * *$ & $.33^{* *}$ & $.32 * *$ & & $.41 * *$ \\
\hline $\begin{array}{l}\text { Self-chang } \\
\text { e }\end{array}$ & .01 & $.13 * *$ & -.04 & $-.03+$ & $.12^{*}$ & $.31^{* *}$ & $.24 * *$ & $.34 * *$ & $.41^{* *}$ & \\
\hline
\end{tabular}

Notes: VSRB- Volitional Sexual Risk Behaviour; NVSRB Non-Volitional Sexual Risk Behaviour

$+n=338 ; \quad * * p \leq .005,{ }^{*} p \leq .05$ 